\title{
Applied and research based performance indicator database for highway bridges across Europe
}

\author{
Alfred. Strauss \& Konrad Bergmeister \\ Department of Civil Engineering and Natural Hazards, Institute of Structural Engineering, University of Nat- \\ ural Resources and Life Sciences, 1190 Vienna, Austria
}

Ana Mandić Ivanković

Department of Structural Engineering, Faculty of Civil Engineering, University of Zagreb, Kačićeva 26, Zagreb 10000, Croatia

Jose Campos e Matos

Department of Civil Engineering, Minho University, Guimarães, Portugal

ABSTRACT: Structural codes provide several practical principles and application rules such as the use of protective systems for material exposed in aggressive environment, the construction detailing aimed at avoiding the initiation of degradation, the maintenance actions to be regularly performed. Each construction, during its life cycle, will face with deterioration depending on several factors such as the environmental condition, the natural aging, the quality of the material, the execution of works and the planned maintenance. Therefore, several design procedures based on the prediction of the deterioration that will likely act on the structure will be developed in the framework of the international research. In addition, performance indicators for the present and future structural conditions on deterministic and probabilistic level will be defined and determined. It is extremely important to analyse such indicators in terms of used assessment frameworks, and in terms of the quantification procedure itself.

\section{INTRODUCTION}

Deterioration could lead to a decrease of performance to such an extent that a structure could not be able to satisfy the basic serviceability and safety requirements before the design life has expired. In order to prevent the premature failure of a construction, structural codes provide several practical principles and application rules such as the use of protective systems for material exposed in aggressive environment, the construction detailing aimed at avoiding the initiation of degradation, the maintenance actions to be regularly performed, etc.

Each construction, during its life cycle, will face with deterioration depending on several factors such as the environmental condition, the natural aging, the quality of the material, the execution of works and the planned maintenance. Therefore, several design procedures based on the prediction of the deterioration that will likely act on the structure will be developed in the framework of the international research. In addition, performance indicators for the present and future structural conditions on deterministic and probabilistic level will be defined and determined.

It is known that management systems are supported in QC plans which in turn are supported by performance indicators. Therefore, it is extremely im- portant to analyse such indicators in terms of used assessment frameworks and in terms of the quantification procedure itself. In particular, the work group 1 of the COST TU 1406 starts with August 2015 and focuses mainly on technical, sustainability indicators and others. The goal in the first step was to explore technical performance indicators of bridge structures, in the course of international research cooperation, which capture the mechanical and technical properties and its degradation behaviour. These properties are already partly covered by norm specifications but not their complex time variable performance. Moreover, environmental condition, natural aging, and the quality of the material regarding to determined indicators have been investigated and evaluated in their meaningfulness. These considerations, however, also include service life design methods, aimed at estimating the period of time during which a structure or any component is able to achieve the performance requirements defined at the design stage with an adequate degree of reliability. On the basis of the quality of input information (mainly concerning with the available degradation models), it is possible to distinguish among deterministic methods, usually based on building science principles, expert judgment and past experience, which provide a simple estimation of the service life, and probabilistic methods. In addition to technical performance indicators, which characterize the ulti- 
mate capacity as well as serviceability conditions, sustainability indicators, environmental based, are also part of WG 1 . These variables characterize the environmental impact of a structure in the course of its total life cycle, expressed in terms of total energy consumption, carbon footprint $\left(\mathrm{CO}_{2}\right.$ emission), balance of raw materials, etc. These indicators can be separated into direct and indirect indicators, where the former are related to the construction/maintenance itself and the latter are caused e.g. as a consequence of limited functionality. In addition, other sustainable indicators, economic and social based, may be used to evaluate a bridge performance. These indicators capture, based on the technical performance of a structure, additional aspects that may influence the decision process and typically represent the discounted (accumulated) direct or indirect costs associated with construction and maintenance. Summed up over the full life-time, they represent part of or the full life-cycle costs. They can, in the context of multi-objective optimization, be understood as a weighting scheme to arrive to a single objective function that is to be minimized. Finally, the objective of the WG1 is the publication of a report on these performance indicators. Such report will address a general description, how they are assessed (e.g. visual inspection, nondestructive tests and monitoring systems), with what frequency, what values are generally obtained and, finally, some general recommendations. Moreover, it is a further goal of working group 1 creating a database with homogenized performance indicators, performance goals and thresholds to provide the basics for quality specifications for roadway bridges at a European level.

\section{PROCEDURE FOR ACQUIRING PERFORMANCE INDICATORS}

The determination of performance indicators for bridge structures from European countries and its harmonization on a European level is complex, extensive, and time consuming. These facts were confirmed in processing WG 1 "Performance indicators" of the COST TU1406 (Matos et al., 2016). There are the following findings and important aspects associated with the Performance Indicator Survey Processes in the first year of COST TU1406, as reported in Casas 2016:

- A complete translation of codes or guidelines as used by owners and operators from the national language to international European format has been considered as unnecessary, since only some pages are devoted to the subject of interest (performance indicator, performance goal,...).

- The nomination of a responsible to collect the relevant parts of existing guidelines and translate them to English turned out to be much more effective. The responsible person must have good knowledge and expertise on inspection/assessment of existing bridges in order to identify the relevant parts.

- A request for replying the questions in the questionnaire, and for up-loading the relevant parts of the document, both the original and the translated versions was regarded as very significant. It supports to objectify the language translations, since (a) it was revealed that many times the same operation or concept has different English translations or wording, and (b) to avoid subjectivity in some way.

- Because of the objective to propose enhancements to the existing practice of performance assessment by the different owners and showing recent advances and new performance indicators two types of documents are asked for: operator documents (actually in use by the different Agencies in the form of guidelines or recommendations) and research documents.

- Due to the different languages used across Europe and the different formats of both type of documents (guideline or research oriented) it was decided to nominate in each country several persons with the following different tasks:

$\circ$ One of the two nominated Management Committee members which are nominated by each participating country (according to COST Action rules) is responsible to contact owners and operators of highway bridges asking for available documents in practice.

o A Core Group of WG1 has been formatted for the preparation of tutorials for the screening of documents, processing screened documents, fillin the data base and finally analyze the data base and to obtain the main results and conclusions.

o A nominated country responsible person is in charge of gathering, screening and processing national applied documents according to some guidelines and tutorials elaborated by the Core Group of the Working Group. He/she is also the responsible, jointly with the nominated person from the MC to identify the research groups in each country and ask them to provide information about new proposal still in the researching phase for performance indicators. 
As mentioned in Casas (2016), the COST TU1406 Geneva Workshop in September of 2015 served to the essential steps of the WG1 to WG3 in order to gather more information related to the performance indicators used in practice and under research. Each WG member was asked (a) in participating in the workshop, and (b) preparing a poster or oral presentations with the following order:

o Extract from the available documents the most important $(>8)$ performance indicators.

o Show the formulation and the procedure on how to obtain the PI.

o Show the thresholds with respect to each PI, if available.

o Show the goals with respect to each PI, if available.

o Characterize, based on their experience, if their indicated or proposed PI are already applied by owners, operators, experts, ..., in which project phases.

o Characterize those PI that are important, but not applied now, or not applied now and needing further investigations in order to become fully implementable.

\section{PERFORMANCE INDICATOR DATA BASE}

For the development of a performance indicator data base from an European perspective it is important to have a general agreement on important definitions. For this procedure we used European standards, background documents for standards such as the Model Code 2010 and approved research reports such as the BAST documents "Intelligente Bauwerke" (Schnellenbach-Held 2014). Some of the most important definitions are shown in the following chapter.

\subsection{Important Definitions}

Asset management: coordinated activities of an organization to realize value from assets; Realization of value will normally involve a balancing of costs, risks, opportunities and performance benefits. (ISO55 000)

Damage: Physical disruption or change in the condition of a structure or its components, caused by external actions, such that some aspect of either the current or future performance of the structure or its components will be impaired. The unfavourable change may refer to a mechanical properties of con- struction materials and/or to geometrical properties of a structural system (including changes to the structural members, member connections, and supports). (SHM Glossary)

Deterioration: Worsening of condition with time, or a progressive reduction in the ability of a structure or its components to perform according to their intended functional specifications. (MC2010)

Deterioration mechanism: (Scientifically describable) process of the cause and development of deterioration. (MC2010)

Damage detection: Process of ascertaining whether the damage to structure exists or not. Three main approaches in damage detection are visual inspection, non-destructive testing, and structural health monitoring. (SHM Glossary)

Damage identification: In addition to damage detection and characterization, damage identification includes ascertaining the cause of the damage and its consequences. (SHM Glossary)

Lifecycle cost (LCC): cost of an asset or its parts throughout its lifecycle, while fulfilling its performance requirements (CEN: Ageing Behaviour of Structural Components for Integrated Lifetime Assessment and Asset Management)

Performance assessment: A set of activities performed to verify the reliability of an existing structure for future use. (CEN - Ageing Behaviour of Structural Components for Integrated Lifetime Assessment and Asset Management)

Performance criteria: Quantitative limits, associated to a performance indicator, defining the border between desired and adverse behaviour (MC2010)

Performance evaluation: process of determining measurable results. (ISO 22301)

Performance goal: Type of bridge property (behaviour) that is required based on assessment of different performance indicators.

Performance index: An assessed parameter of the bridge, dimensionless number or letter on a scale that evaluates the parameter involved on an $\mathrm{X}$ to $\mathrm{XN}$ scale, $\mathrm{X}$ being a very good condition and $\mathrm{XN}$ a very poor one.

Performance indicator: A superior term of a bridge characteristic, which indicates the condition of a bridge. It can be expressed in the form of a dimensional performance parameter or as a dimensionless performance index.

Measurable/testable parameter (i.e. characteristic of materials and structures) that quantitatively describes a performance aspect. (MC2010)

Performance level: Qualification of a structure or a structural element, which is established by verifying its behaviour against the performance requirements. 
A satisfactory performance level is reached when a structure or a structural element has demonstrated a sufficient behaviour to meet the performance requirements. In the opposite case, the performance level of a structure or a structural element is considered to be unsatisfactory.

Performance threshold: A value that constitutes a boundary for purposes such as: a) monitoring (e.g. an effect is observed or not), b) assessing (e.g. an effect is low or high), and c) decision-making (e.g. an effect is critical or not). (IRIS - Glossary of risk related terms)

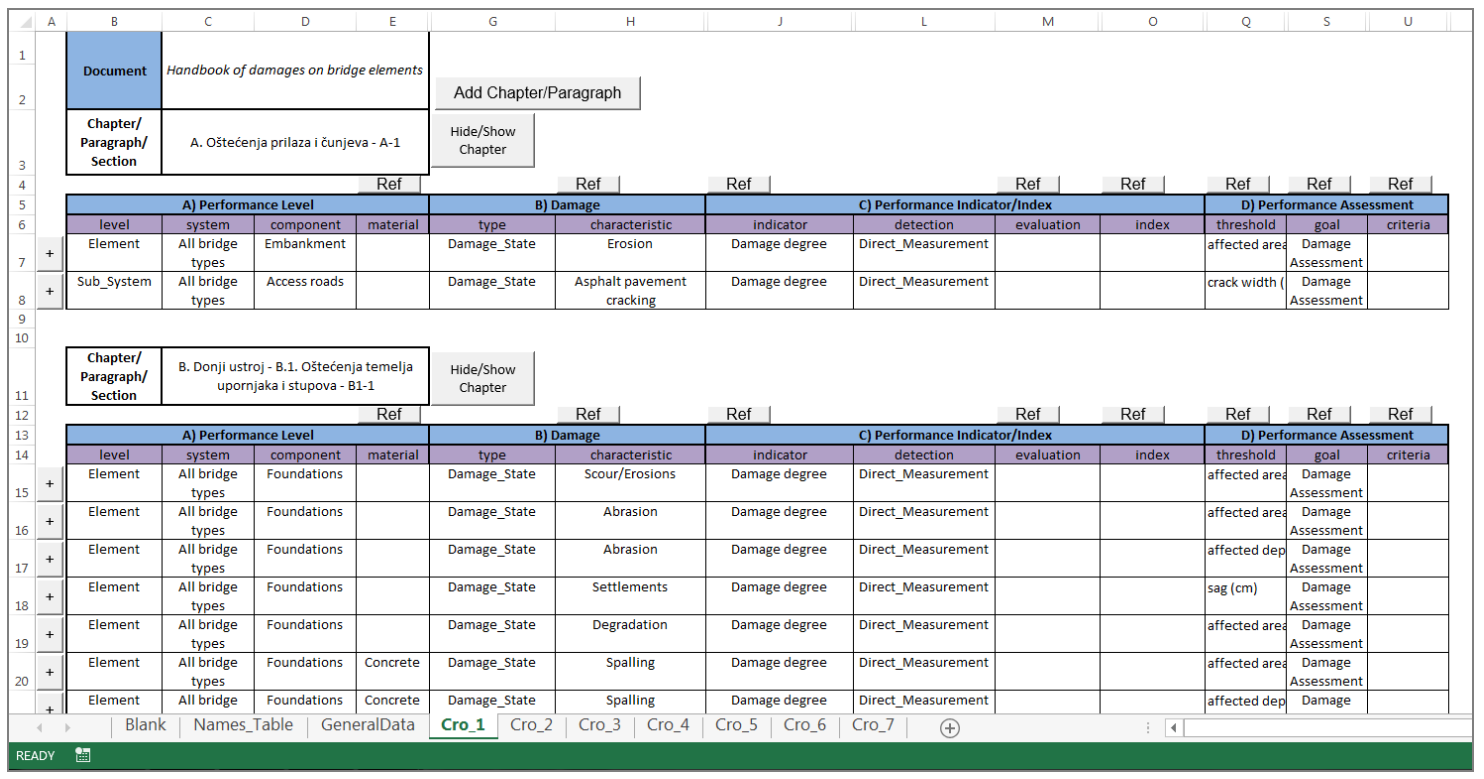

Fig. 1. User interface for the screening process of the Performance indicator of the PI database from an European perspective (Strauss et al. 2016 (a), (b))

\begin{tabular}{|c|c|c|c|c|}
\hline Country & Document & Doc. Type & Author & Year \\
\hline Austria & Quality Assurance for Structural Maintenance - Suveilance, Checking and As & Inspection & BMVIT & 2011 \\
\hline \multirow[t]{7}{*}{ Bosnia and Herz. } & ZAKON O CESTAMA FEDERACIJE BOSNE I HERCEGOVINE / LAW ON ROADS OF & Inspection & Parlament Federacije BiH / Federation Parl & 2010 \\
\hline & Odluka o kategorizaciji cesta u autoceste i brze ceste, magistralne ceste i re & Inspection & Vlada FBiH / Government of FBiH & 2014 \\
\hline & Pravilnik o održavanju javnih cesta / Regulations the maintenance of public & Inspection & Federalnom ministarstvu prometa i komuni & 2010 \\
\hline & SMJERNICE ZA PROJEKTOVANJE, GRAĐENJE, ODRŽAVANJE I NADZOR NA CES & glnspection & RS-FB\&H/3CS - DDC & 2005 \\
\hline & UPUTSTVO ZA INSPEKTORE MOSTOVA / INSTRUCTIONS FOR INSPECTORS OF & Evaluation & BCEOM Societe Francaise D'Ingenere & 2004 \\
\hline & MOSTOVI / BRIDGES & Research & Prof. Boris Koboević, $\quad$ Prof. Bisera Karal & 1994 \\
\hline & Inspekcijski formular za pregled mosta / The inspection form for an overvie & Inspection & Prof. Bisera Karalić-Hromić & 2004 \\
\hline \multirow[t]{7}{*}{ Croatia } & Handbook of damages on bridge elements & Evaluation & Hrvatske ceste d.o.o., dr.sc. Danijel Tenžera & 2014 \\
\hline & Guidelines for bridge inspections & Inspection & Hrvatske ceste d.o.o. & 2014 \\
\hline & HRMOS manual - Bridge management & Inspection & Hrvatske ceste d.o.o. & 1999 \\
\hline & HRMOS manual - Bridge management - General bridge inspection & Inspection & Hrvatske ceste d.o.o. & 1999 \\
\hline & Handbook of damages on bridges & Inspection/evaluatic & cHrvatske Autocesete d.o.o. & 2010 \\
\hline & Guideline for bridge evaluation & Evaluation & Hrvatske Autocesete d.o.o. & 2010 \\
\hline & Bridge Management Planning & Background docume & Hrvatske Autocesete d.o.o. & 2008 \\
\hline \multirow[t]{12}{*}{ Czech Republic } & ČSN 736221 Inspection of road bridges & Inspection & UNMZ Ústav pro technickou normalizaci, me & 2011 \\
\hline & ČSN 736222 Load capacity of road bridges & Evaluation & UNMZ Ústav pro technickou normalizaci, me & 2009 \\
\hline & Catalouge of the bridge damages and defects & Inspection & Pontex spol.s r.o. & 2008 \\
\hline & TP72 Diagnostics of road bridges & Inspection & Pontex spol.s r.o. & 2008 \\
\hline & TRP201 Measuring and monitoring of the cracks in the concrete bridges & Inspection & CTU in Prague, Klokner institute & 2008 \\
\hline & ČSN 736209 Load tests of bridges & Evaluation & UNMZ Ústav pro technickou normalizaci, me & 1996 \\
\hline & Damages of railway bridges & Inspection & SŽDC TÚDC & 2009 \\
\hline & Rules for the assesment of the load capacity of railway bridges & Evaluation & SŽDC TÚDC & 2014 \\
\hline & SŽDC S5 management of bridges(railway) & Inspection & SŽDC TÚDC & 2012 \\
\hline & TP120 Maintenance, repairs and refurbishment of concrete road bridges & Inspection & Pontex spol.s r.o. & 2010 \\
\hline & TP175 Evaluation of the remaining life of concrete road structures & Evaluation & SVúoM s.r.o. & 2006 \\
\hline & TP215 The application of the modal analysis for the road bridges evaluation & Evaluation & CTU in Prague, Faculty of civil eng. & 2009 \\
\hline
\end{tabular}

Fig. 2. Codes or guidelines for the screening process (Strauss et al. 2016 (a), (b)) 
Reliability: The probability that a system or component will meet its performance requirements under given conditions and during a given period of time.

Repair: Improvement of the conditions of a structure by restoring or replacing existing components that have been damaged. (SAMCO)

Service life: period of time after installation during which a facility, or its component parts, meets or exceeds the performance requirements (CEN: Ageing Behaviour of Structural Components for Integrated Lifetime Assessment and Asset Management)

Serviceability: the ability of a structure to be serving or capable of serving its intended purposes to the uses' satisfaction. (SAMCO)

\subsection{Collecting - Procedure}

In parallel to the filling of the questionnaire and the development of the Performance Indicator database, see Fig. 1, as described in paragraph 2, a glossary of terms was formed to support the survey process that contains informations and definitions related to performance indicators/goals/thresholds, inspections etc. based on the BAST documents "Intelligente Bauwerke" (Schnellenbach-Held 2014). This Glossary served in parallel to the prepared database sheet as background document in the process of survey and screening the codes or guidelines as used by owners and operators. As shown in Fig. 1 the Database User interface for the survey is structured in MS Excel, where the data is structured in four groups (Casas, 2016, Strauss et al., 2016 (a), (b)): Performance Level, Damage, Performance Indicator/Index and Performance Assessment. The users should fill up the data in these groups and update the Glossary information at the same time.

As mentioned previously, the nominated country responsible persons, in charge of gathering, screening and processing national applied documents, provided also the information about the performance assessment of structures essential national documents, as shown in Figure 2.

\section{CATEGORIZATION OF THE PERFORMANCE INDICATOR DATA BASE}

The PI related information from the screening process of the 34 countries are diverse and require an additional categorization (Strauss et al. 2016(b)). It is also a dominant theme of COST TU 1402 "Quatifaying the value of Structural health monitoring". A proposal for the categorization has been developed together with representatives of COST 1406, Strauss et al., 2016 (a), (b)).
In the following section there is a small outline of a categorization proposal.

\subsection{Performance indicators at the component level}

Bridge inspection is general carried out by bridge elements (components) forming three main bridge sub-systems: substructure, superstructure and roadway. Bridge components including constitutive materials are given in table 1 .

\subsubsection{Technical indicators}

At the bridge component level, one of the important performance goal to be reached is damage assessment. This implies detection of damages but also their identification and evaluation. Damage of a bridge element is physical or chemical disruption or change in its condition, caused by external actions and/or conditions, such that some aspect of, either the current or future performance of the component (and perhaps consecutively a complete structure) is impaired.

Four main approaches in damage detection are visual inspection, nondestructive testing, probing and structural health monitoring. In addition to damage detection and characterization, damage identification includes ascertaining the cause of the damage and its consequences and damage evaluation comprises degree or/and extend with respect to the set threshold value.

Besides most commonly set up upper limit, additional threshold in the damage assessment may be duration of damage phase, which will give a clue in which phase of damage progress the element is find: low, moderate or high. The former will request the protection from further progression, the second one will require a routine repair and the last one requests more detailed inspections and testing leading to a routine or special repair.

Upon assessing damages of a particular bridge element, the component functionality level may be evaluated. Element may be evaluated in best condition when no damage is detected, with unquestionable function when damage is in initial phase, with function not been compromised when damaged is moderate and with questionable function or element is out of function when damage has high degree and/or extend. 


\subsubsection{Socio-economic indicators}

At this level socio-economic aspects are to be included. A ratio of sum of costs for repair of individual damages and price of the new element is an indicator of the element's general condition assessment. Threshold for this indicator may be set as quantitative scale of value showing gradation of element condition assessment. For all elements for which this ratio is above 1.0 replacement with a new element should be predicted.

Table 1. Bridge elements for categorization at the component level

\begin{tabular}{ccc}
\hline Substructure & Superstructure & $\begin{array}{c}\text { Roadway + } \\
\text { equipment }\end{array}$ \\
\hline $\begin{array}{c}\text { Foundations } \\
\text { (concrete) }\end{array}$ & $\begin{array}{c}\text { Superstructure } \\
\text { (reinforced con- } \\
\text { crete) }\end{array}$ & Pavement \\
\hline $\begin{array}{c}\text { Deep founda- } \\
\text { tions, piles (con- } \\
\text { crete) }\end{array}$ & $\begin{array}{c}\text { Superstructure } \\
\text { (prestressed con- } \\
\text { crete) }\end{array}$ & $\begin{array}{c}\text { Curb \& Cor- } \\
\text { nices }\end{array}$ \\
\hline $\begin{array}{c}\text { Deep founda- } \\
\text { tions, piles (steel) }\end{array}$ & $\begin{array}{c}\text { Superstructure } \\
\text { (steel) }\end{array}$ & $\begin{array}{c}\text { Railings \& } \\
\text { railing anchorage, } \\
\text { barriers }\end{array}$ \\
\hline $\begin{array}{c}\text { Deep founda- } \\
\text { tions, piles (tim- } \\
\text { ber) }\end{array}$ & $\begin{array}{c}\text { Superstructure } \\
\text { (composite) }\end{array}$ & $\begin{array}{c}\text { Sidewalk (Pe- } \\
\text { destrian walkway) }\end{array}$ \\
\hline $\begin{array}{c}\text { Abutments } \\
\text { (concrete) }\end{array}$ & $\begin{array}{c}\text { Superstructure } \\
\text { (timber) }\end{array}$ & Bearings \\
\hline $\begin{array}{c}\text { Abutments } \\
\text { (masonry) }\end{array}$ & $\begin{array}{c}\text { Superstructure } \\
\text { (brick) }\end{array}$ & $\begin{array}{c}\text { Expansion } \\
\text { joints }\end{array}$ \\
\hline Piers (concrete) & $\begin{array}{c}\text { Superstructure } \\
\text { (stone) }\end{array}$ & Drainage \\
\hline Piers (steel) & Arch (concrete) & Lighting \\
\hline Piers (masonry) & Arch (masonry) & Signalization \\
\hline & &
\end{tabular}

\subsection{Performance indicators at the system level}

In order to assess the impact of the damaged element functionality to the entire structure, the importance of bridge element is to be evaluated according to following criteria: structural safety and serviceability, traffic safety and durability (Ahrens et al. 2013). Qualitative scale of values may show how the collapse of a particular element would affect each criteria. Besides technical indicators, at this level sustainability and socio-economic indicators will assume essential impact to performance requirements.

Additionally, indicators related to scientific achievements in, for example, testing and monitoring, dynamic behavior and reliability of bridge structures should be included at this level, as well. Some contemplation on those indicators will be given after the survey of research based indicators at the European level. For example, bridge reliability assess- ment will require adequate knowledge level on bridge properties such are for example stiffness changes and realistic traffic loading which requires investment in additional inspection, testing or monitoring method, advanced modeling techniques and updating data on bridge resistance and loads.

\subsubsection{Technical indicators}

Technical indicators at this level are those related to bridge safety and serviceability as main performance goals used in existing inspection and evaluation documents. Based on this criteria, it may be decided that collapse of particular element will have no influence to safety and serviceability of the bridge, has influence to a part of a bridge structure or has influence to an entire bridge structure.

\subsubsection{Sustainable and durability indicators}

When meeting performance requirements is evaluated, under given condition during a given period of time, sustainability issues occur. Therefore durability may be considered as sustainable performance goal which needs to be included as a criteria for condition assessment of bridge sub-systems comprising roadway, substructure and superstructure and for entire bridge condition assessment. Based on durability criteria, it may be decided that collapse of particular element will have no influence to durability of other components or contrary that collapse of particular element will cause reduced durability of other components.

\subsubsection{Socio-economic (traffic safety) indicators}

Traffic safety may be considered as socio-economic performance goal. Namely, as criteria for condition assessment of bridge sub-systems or entire bridge condition assessment, it is expressed in levels of traffic limitation or congestion: collapse of a particular element has no influence to traffic flow, causes speed limitation, causes local traffic redirection or complete traffic suspension.

Additional indicator to be raised at the system level is element general condition assessment, which will help to assess the condition of a sub system and entire bridge.

\subsection{Performance indicators at the network level}

At the network level, based on the bridge condition assessment gained through standard inspection and evaluation procedures with additional evaluation of 
bridge importance in the network, the primary goal to be reached is priority repair ranking.

Bridge condition assessment based on four criteria: structural safety and serviceability, durability, traffic safety and general bridge condition, may be contemplated as sustainability indicators at the network lev- el. On the other hand, bridge importance in the network, which is based on five criteria - road category, annual average daily traffic, detour distance, largest span, total length - may be considered as socioeconomic indicator.

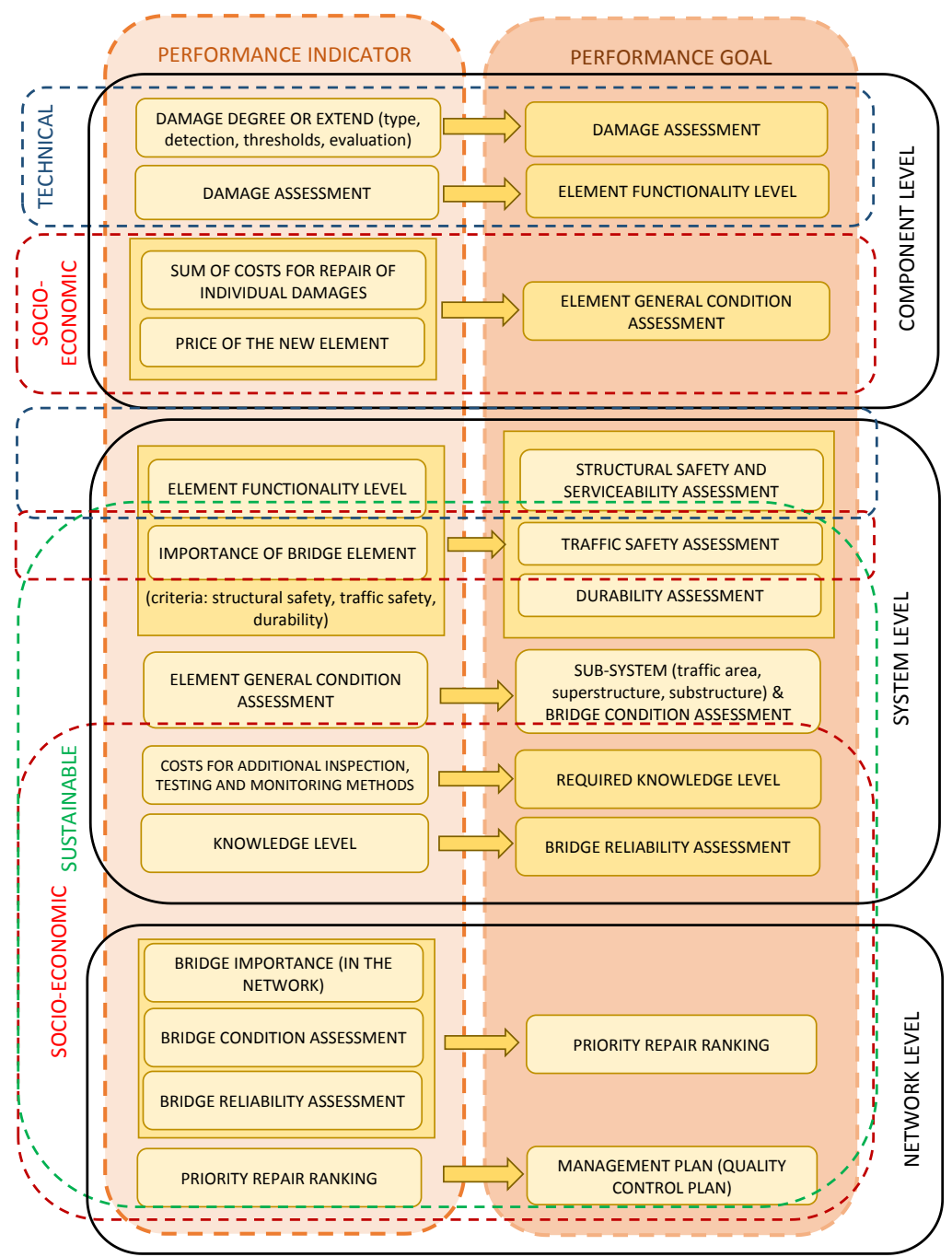

Fig. 3.: Performance indicator-goals categorization and synchronization of the database content (Strauss et al. 2016 (a),(b))

Criteria related to bridge condition are based on damage assessment procedure overviewed in this paper based on existing inspection and evaluation documents. The first three criteria related to bridge importance - road category, annual average daily traffic and detour distance - are mutually independent and equally important for decision on bridge importance. Criteria of the largest span and criteria of the total length describe the common demands on the construction and property value and therefore their importance in total may be considered as equal to other criteria. Criteria are reduced to the comparable values with the help of preference functions and adequate threshold of indifference and preference for each criteria (Croatian highways ltd. 2008). 
At this level indicators related to scientific achievements such is bridge reliability assessment, should be continuously developed from previous level and included into priority repair ranking. Priority repair ranking, at the same time, is essential indicator for final goal: optimal management plan of roadway bridges, which is to be evaluated through decision ranking (by power and weakness of decisions).

\subsubsection{Categorization of the Performance Indicator Data Base}

The data in the Performance Indicator DataBase of the first screening process of the 36 countries are partly heterogeneous and overlapping despite the detailed developed guidelines and glossary. It mainly results from free interpretation leeway and the different experience grade of nominated screening people in visual inspections, performance evaluation, performance assessment and decision making. Therefore the second COST TU1406 Budapest Workshop in January 2016 was used to discuss with the screening nominated people the screening process, missing elements, misinterpretations among others, and to define with them the following working program: (a) Completion of missing PI associated data sheets; (b) critical review of individual screening results based on the database inputs from other countries; (c) request for a critical feedback with respect to the content and the definitions in the developed PI database from MC members, from national bridge owners, bridge inspectors and inspectors commissioned by bridge owners. This feedback and review processes allow a fundamental PI-PG categorization and a synchronization of the database content at an European level, as shown in Fig. 3 (Strauss et al. 2016 (a), (b)).

\section{RESULTS}

In all the surveyed countries, there exist guidelines, recommendations or codes to define the quality level of the existing highway bridges. In table at the figure $2+$ are summarized the surveyed documents in different countries. In figure 13 , there is an example on how the filled material in the Excel sheet looks like. As expected, the information provided by each country is quite heterogeneous, despite the tutorial prepared to facilitate the input of data. In some way, there is a misunderstanding about what a performance indicator is and how is it obtained.

\section{ACKNOWLEDGMENTS}

This article is based upon work from COST Action TU-1406, Quality specifications for roadway bridges, standardization at a European level (BridgeSpec), supported by COST (European Cooperation in Science and Technology).

\section{REFERENCES}

Ahrens, M. A.; Strauss, A.; Bergmeister, K.; Mark, P.; Stangenberg, F. (2013): Lebensdauerorientierter Entwurf, Konstruktion, Nachrechnung. Grundlagen und numerische Simulation. Ingenieurwissenschaftliche und baupraktische Methoden.. In: Bergmeister; Fingerloos; Wöhrner (Hrsg.), Beton Kalender 2013 Band 1, 19 - 222; Wilhelm Ernst \& Sohn Verlag, Berlin; ISBN 978-3-433-03000-4

Casas, J.R. 2016. European Standardization of Quality Specifications for Roadway Bridges: an Overview. Proceedings $8^{\text {th }}$ international conference on Bridge Maintenance, Safety and Management, Foz do Iguaçu (Brazil), 26-30 June 2016. London: Taylor and Francis.

Croatian highways ltd. 2008. Bridge management planning, document of Building Management System of Croatian highways. Zagreb, Croatia

Hajdin R. 2016. Quality control plans on roadway bridges. Proceedings 8th international conference on Bridge Maintenance, Safety and Management, Foz do Iguaçu (Brazil), 26-30 June 2016. London: Taylor and Francis

Matos J.C., Casas J.R., Fernandes S. 2016. COST Action TU 1406 Quality Specifications for Roadway Bridges (BridgeSpec). Proceedings $8^{\text {th }}$ international conference on Bridge Maintenance, Safety and Management, Foz do Iguaçu (Brazil), 26-30 June 2016. London: Taylor and Francis.

Schnellenbach-Held, M., Karczewski, B., Kühn, O (2014) Intelligente Brücke - Machbarkeitsstudie für ein System zur Informationsbereitstellung und ganzheitlichen Bewertung in Echtzeit für Brückenbauwerke BASt-Bericht B 105 Universität Duisburg-Essen, Institut Massivbau, Fachverlag NW in der Carl Schünemann Verlag GmbH.

Stipanovic I. and Klanker G. 2016. Performance goals for roadway bridges. Proceedings $8^{\text {th }}$ international conference on Bridge Maintenance, Safety and Management, Foz do Iguaçu (Brazil), 26-30 June 2016. London: Taylor and Francis.

Strauss A., Mandić Ivanković A. (2016). Performance indicators for road bridges - categorization overview. Paper prepared for WG meeting of COST action TU1406 Quality specifications for roadway bridges, standardization at a European level, 30th March -1st April, 2016, Belgrade, Serbia

Strauss A., Vidovic A, Zambon I., Dengg F., Tanasic N., Campos J.C. 2016. Performance indicators for roadway bridges. Proceedings $8^{\text {th }}$ international conference on Bridge Maintenance, Safety and Management, Foz do Iguaçu (Brazil), 26-30 June 2016. London: Taylor and Francis.

Strauss, A., Bergmeister, K., Novák, D., Lehký, D. 2004. Probabilistic response identification and monitoring of concrete structures Beton- und Stahlbetonbau, 99 (12), pp. 967-974.

Strauss, A., Wendner, R., Frangopol, D.M., 2012 Bergmeister, $\mathrm{K}$. Influence line-model correction approach for the assessment of engineering structures using novel monitoring techniques. Smart Structures and Systems, 9 (1), pp. 1-20.

Zimmermann, T., Strauss, A., Bergmeister, K. 2010. Numerical investigation of historic masonry walls under normal and shear load. Construction and Building Materials, 24 (8), pp. 1385-1391.

Strauss, A., Zimmermann, T., Lehký, D., Novák, D., Keršner, Z. 2014. Stochastic fracture-mechanical parameters for the performance-based design of concrete structures. Structural Concrete, 15 (3), pp. 380-394. 